\title{
Homogeneous nucleation rates of nitric acid dihydrate (NAD) at simulated stratospheric conditions - Part I: Experimental results
}

\author{
O. Stetzer ${ }^{1,2}$, O. Möhler ${ }^{2}$, R. Wagner ${ }^{2}$, S. Benz ${ }^{2}$, H. Saathoff ${ }^{2}$, H. Bunz ${ }^{2}$, and O. Indris ${ }^{3}$ \\ ${ }^{1}$ Institute for Atmospheric and Climate Science, ETH Zurich, Switzerland \\ ${ }^{2}$ Institut für Meteorologie und Klimaforschung, Forschungszentrum Karlsruhe, Germany \\ ${ }^{3}$ Max-Planck-Institut für Kernphysik, Abt. Atmosphärenphysik, Heidelberg, Germany
}

Received: 23 December 2005 - Published in Atmos. Chem. Phys. Discuss.: 28 March 2006

Revised: 28 June 2006 - Accepted: 11 July 2006 - Published: 24 July 2006

\begin{abstract}
The low temperature aerosol chamber AIDA was used to study the nucleation of nitric acid dihydrate (NAD) in super-cooled nitric acid aerosols under simulated stratospheric conditions in the temperature range $192 \mathrm{~K}-197 \mathrm{~K}$. The nucleating solution droplets had median diameters between 225 and $290 \mathrm{~nm}$ and molar fractions of nitric acid between 0.26 and 0.28 . Nucleation of solid particles was unambiguously observed in two out of three experiments during time periods of up to five hours. The newly formed crystals could be clearly distinguished from the remaining liquid droplets by their increasing size with an optical particle spectrometer. The solid particles could be unequivocally identified as strongly aspherical nitric acid dihydrate crystals $(\alpha-$ NAD) by in-situ FTIR-spectroscopy. From our experimental data set there is no indication of direct nucleation of NAT or a conversion of NAD into NAT while having saturation ratios with respect to NAT of about 20-26. The temporal evolutions of the NAD particle concentrations were used to derive individual nucleation rates for NAD. The measured volume nucleation rates ranged from $3.9 \times 10^{5} \mathrm{~cm}^{-3} \mathrm{~s}^{-1}$ at $195.8 \mathrm{~K}$ and $X_{\mathrm{NA}}=0.27$ to $1.9 \times 10^{7} \mathrm{~cm}^{-3} \mathrm{~s}^{-1}$ at $192.1 \mathrm{~K}$ and $X_{\mathrm{NA}}=0.28$. The corresponding hypothetical surface nucleation rates of $2 \times 10^{0}$ to $1 \times 10^{2} \mathrm{~cm}^{-2} \mathrm{~s}^{-1}$ are smaller than the parameterization of Tabazadeh et al. (2002) by factors between 25 and $>10^{3}$.
\end{abstract}

\section{Introduction}

Since the discovery of the ozone hole in 1985 (Farman et al., 1985) and the mechanisms that led to the ozone destruction over Antarctica (Crutzen and Arnold, 1986; Molina and Molina, 1987) there has been an increasing interest in

Correspondence to: O. Stetzer

(olaf.stetzer@env.ethz.ch) the evolution and composition of polar stratospheric clouds (PSCs) which play a crucial role in the destruction of stratospheric ozone in the polar winters (McElroy et al., 1986; Solomon et al., 1986; Molina, 1991). PSCs are mostly liquid droplets, denoted as PSC type Ib particles, consisting of sulphuric acid, nitric acid, and water (STS) with compositions that vary strongly with decreasing temperature (Carslaw et al., 1994). At the lowest temperatures that occur in the polar winter stratosphere PSC particles can freeze to become ice particles (PSC type II) or solid nitric acid hydrates (PSC type Ia) such as nitric acid dihydrate or trihydrate (NAD, NAT). There have been some evidences for the presence of STS, NAT and ice in PSCs (Schreiner et al., 1999; Voigt et al., 2000) which were only recently further supported by spectroscopic measurements (Hopfner et al., 2006).

One key component in the ozone destruction cycle is nitric acid and its "family" members, collectively denoted as $\mathrm{NO}_{\mathrm{y}}$. These substances are capable of deactivating the ozone destruction agent $\mathrm{Cl}$ under certain conditions by forming chlorine reservoir species (Solomon, 1999). When NAD or NAT particles form in PSCs they eventually can grow to sizes of a few microns and sediment out to lower layers in the atmosphere. This process is called denitrification because it can lead to a strong depletion of $\mathrm{NO}_{\mathrm{y}}$ in the polar stratosphere and thereby enhance the destruction of ozone because active chlorine no longer can be trapped into the reservoir species. However, it is still not entirely clear which of the different nitric acid hydrate phases (see below) forms in PSCs and what conditions and mechanisms are driving these phase changes.

Both NAD and NAT are known to crystallize in two different phases, the low temperature phases called $\alpha$-NAD and $\alpha$ NAT and the high temperature phases $\beta$-NAD and $\beta$-NAT. In laboratory studies which investigated the crystallization behavior and structure of these phases by X-ray powder diffraction and FTIR spectroscopy (Tisdale et al., 1997; Tizek et al.,

Published by Copernicus GmbH on behalf of the European Geosciences Union. 
2002; Grothe et al., 2004) $\alpha$-NAD and $\alpha$-NAT were typically nucleated by shock freezing of nitric acid solutions with different molar composition. Tisdale et al. (1997) for instance induced the nucleation of $\alpha$-NAT by cooling of liquid thin films with a stoichiometric water to nitric acid molar ratio of 3:1 to temperatures below about $170 \mathrm{~K}$. Conversion of the thin films to $\beta$-NAT occurred upon warming to higher temperatures. Grothe et al. (2004) nucleated the two NAD modifications by shock freezing liquid nitric acid solution droplets of different molar compositions deposited to a sample support which was cooled to $80 \mathrm{~K}$. Subsequent annealing upon warming to temperatures above $180 \mathrm{~K}$ led to the formation of almost pure $\beta$-NAD when starting with liquid aerosols of $2: 1$ water to nitric acid molar ratio. Nonstoichiometric compositions favored the predominant formation of $\alpha$-NAD.

Currently, there are two possible mechanisms being discussed that try to explain and parameterize the formation of nitric acid hydrates by homogeneous nucleation out of liquid PSC droplets: The first parameterization is based on classical nucleation theory which assumes that nucleation takes place in the volume of a droplet (Salcedo et al., 2001). These authors found that $\Delta G_{\text {act }}$ is a linear function of $S_{\mathrm{NAD}}$ in the investigated range of saturation ratios. Knopf et al. (2002) pointed out that the linear $S_{\mathrm{NAD}}$-dependence may not be extrapolated to lower saturation ratios. A new parameterization (Tabazadeh et al., 2002) suggests that nucleation takes place at the surface of a particle. There is an ongoing debate on the validity and applicability of these two mechanisms (Tabazadeh, 2003; Kay et al., 2003). Both mechanisms including the modifications suggested by Knopf et al. (2002) have already been used in modeling studies (e.g. Drdla and Browell, 2004) but there is still a lack in agreement with measured denitrifications. In a recent study the validity of volume-based nucleation for ice nucleation in water droplets could be demonstrated (Duft and Leisner, 2004). However, the authors stress the fact that their conclusion is limited to relatively large droplets with diameters $>8 \mu \mathrm{m}$.

In this paper we describe experiments with the AIDA chamber (Aerosol Interactions and Dynamics in the Atmosphere) where we investigated the nucleation of nitric acid hydrates under PSC conditions. In particular, we are able to experiment with a large quantity of very small droplets. In contrast to flow-tube experiments (Bertram and Sloan, 1998) we can observe chemical compositions and size distributions of particles for a couple of hours which enables us to conduct experiments with lower supersaturations and nucleation rates which are closer to the conditions prevalent in polar stratospheric clouds. We are also able to test recent assumptions that NAT may form immediately out of freshly nucleated NAD crystals (Tabazadeh et al., 2001; Larsen et al., 2004).

Based on the experimental results a new parameterization of the activation energy for the nucleation of NAD as a function of temperature and the saturation ratio with respect to NAD is suggested and compared in a process modeling study to the parameterizations given by Salcedo et al. (2001) and Tabazadeh et al. (2002). Those results are discussed in a companion paper (Möhler et al., 2006).

\section{Experimental}

\subsection{The experimental facility: AIDA}

The experiments were carried out in the aerosol chamber AIDA of Forschungszentrum Karlsruhe which is described in detail in Möhler et al. (2003). Briefly, the chamber consists of an aluminum vessel with a volume of $84 \mathrm{~m}^{3}$ which is placed inside a thermostated housing. By using liquid nitrogen as a coolant the chamber can be operated at temperatures as low as $183 \mathrm{~K}$ with reduced pressures similar to conditions that occur in the polar stratosphere during winter. A variety of instruments is attached to the chamber in order to measure temperature, pressure, trace gases, and aerosol parameters such as number concentrations and size distributions (cf. Fig. 1). Some of the instruments were modified in order to operate at these low temperatures and reduced pressures (Seifert et al., 2004). The instruments used in this study are a FTIR-spectrometer, a chilled mirror hygrometer, a tunable diode laser system (TDL) to measure in situ water vapor, and optical particle spectrometers.

FTIR-measurements are done in-situ with a White-type multiple reflection cell with an optical path of up to $254.3 \mathrm{~m}$. Spectra are recorded with a Bruker IFS 66v FTIR spectrometer in the wave number range from $\tilde{v}=800$ to $6000 \mathrm{~cm}^{-1}$ at a resolution of $4 \mathrm{~cm}^{-1}$. The optical setup and the retrieval of aerosol parameters from raw data is described in detail in Wagner et al. (2003, 2005).

Particle size distributions were measured using an optical particle spectrometer (WELAS, PALAS GmbH). In order to avoid any changes in particle size due to evaporation, the sampling line and the WELAS detector itself were held at the same temperature as the AIDA chamber by placing the detector inside the cooled housing of the chamber directly underneath the AIDA vessel. As the detection efficiency of the WELAS spectrometer decreases for particles smaller than about $1 \mu \mathrm{m}$, correction factors were determined independently of this study and used to calculate the corrected particle number concentrations for this size range. This has been done by size selecting a small mode of DEHS particles with a DMA. The particle concentration of this mode was then counted simultaneously with the WELAS instrument and a CPC. The correction factor was derived by dividing the two signals assuming that the CPC measures correctly. The counting error after this correction is conservatively estimated as $40 \%$ or less.

The size determination relies on the scattering intensities for single particles and thereby on the refractive index and particle shape. For spherical solution droplets the actual particle size was calculated using Mie theory with a refractive 


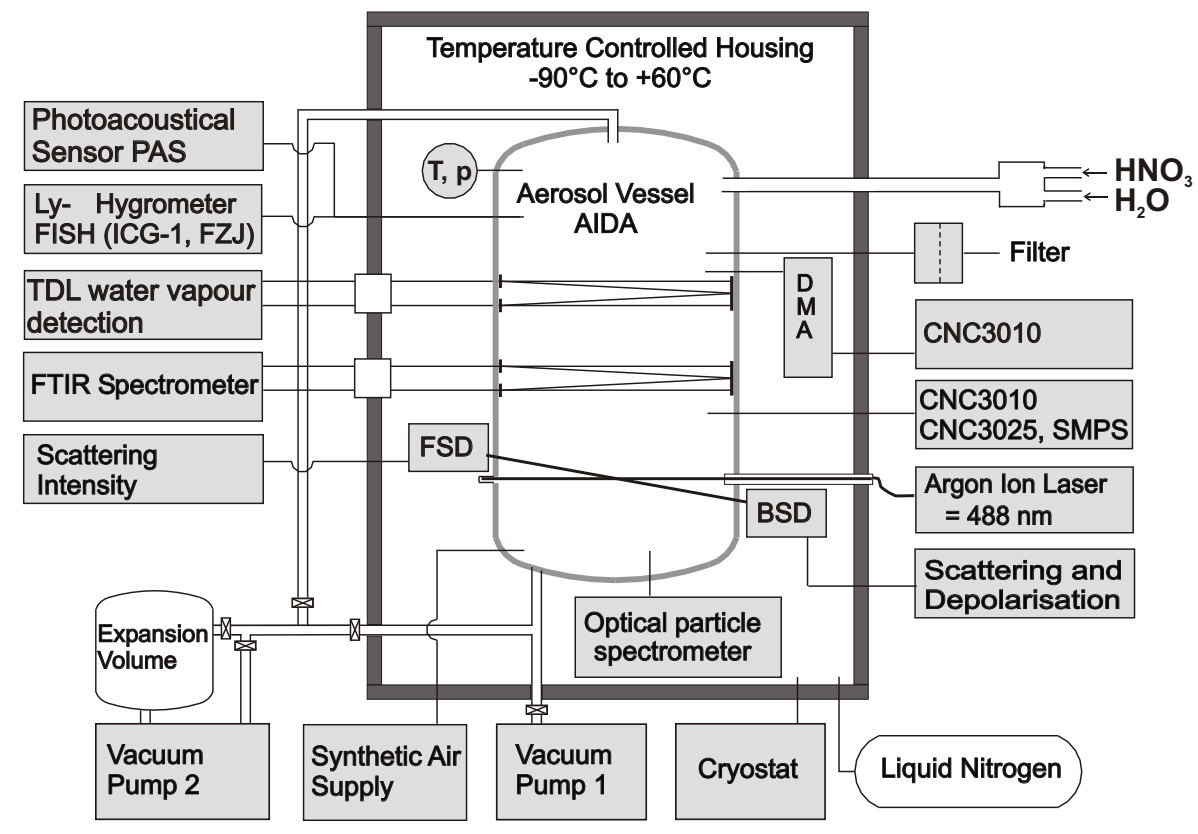

Fig. 1. Schematic view of the aerosol chamber AIDA, showing the major instrumentation used in this study.

index of 1.45 and taking into account the geometry and spectrum (white light) of the WELAS detector (see also: Benz et al., 2005). The deviation between 1.45 and the true refreactive index of the droplets is less than 0.02 which results in an error of not more than $10 \%$ for the reported particle diameter. We made no attempt to correct this data for shape effects to estimate the sizes of the nonspherical NAD particles. All sizes given for NAD particles should be strictly interpreted as optical diameters and not as geometric diameters. The actual geometric sizes can be markedly smaller than the optical diameters given that the NAD particles were oblate and had aspect ratios of more than five (Wagner et al., 2005).

Water vapor concentrations in the AIDA vessel are measured in-situ with a tunable diode laser absorption spectrometer (Ebert et al., 2005). It is fiber-coupled to a White type multi-path cell with $82 \mathrm{~m}$ optical path within the AIDA chamber. Water absorption lines in the spectral region 1368$1372 \mathrm{~nm}$ can be selected to measure water concentrations between 0.01 and $500 \mathrm{~Pa}$ with a time resolution of about $1.5 \mathrm{~s}$, an accuracy of $5-10 \%$, and a resolution in the $\mathrm{H}_{2} \mathrm{O}(\mathrm{g})$ mixing ratio of up to $15 \mathrm{ppb}$. The applied data evaluation procedures are similar to those for earlier in situ TDL spectrometers, which were developed e.g. for a sampling-free detection of CO in power plants (Teichert et al., 2003).

\subsection{Experimental implementation}

Prior to experimentation the saturation ratios with respect to NAD and NAT were calculated for a variety of different conditions (temperature, relative humidity) using the online version of the AIM model described in Clegg et al. (1998).
Some scenarios from these calculations having temperatures between 192 and $198 \mathrm{~K}$ were chosen as being appropriate for NAD/NAT nucleation experiments in the AIDA chamber. In particular, we tried to find conditions where supersaturations with respect to the hydrates NAD and NAT were as high as possible for a given temperature. It turned out that this is achieved by using very dry conditions. Hence, we used a dry AIDA chamber for this study in contrast to ice nucleation studies (Möhler et al., 2003; Moehler et al., 2005).

For a typical experiment the chamber was cooled to the desired temperature using liquid nitrogen. The evacuated chamber was then filled with dry synthetic air to a total pressure of about $180 \mathrm{hPa}$. This yielded an almost particle-free simulation atmosphere with a background concentration of $0.1 \mathrm{~cm}^{-3}$ which has been measured with a condensation particle counter (model 3010, TSI Inc.) Simultaneously, background count rates with the optical WELAS instrument were zero. The relative humidity was around $10 \%$ with respect to ice. To produce the liquid aerosol particles two individual flows of synthetic air were passed through saturators filled with water and pure nitric acid. The saturators were held at temperatures of $10^{\circ} \mathrm{C}$ and $-15^{\circ} \mathrm{C}$, respectively, to maintain constant partial pressures for these components. The two gas flows were then merged and injected into the cold chamber through a heated teflon tube. Upon reaching the cold interior the two gases experienced a high supersaturation and condensed immediately into supersaturated nitric acid/water droplets.

The interior of the chamber was stirred with a fan to achieve homogeneous conditions with a mixing time scale of several minutes. 

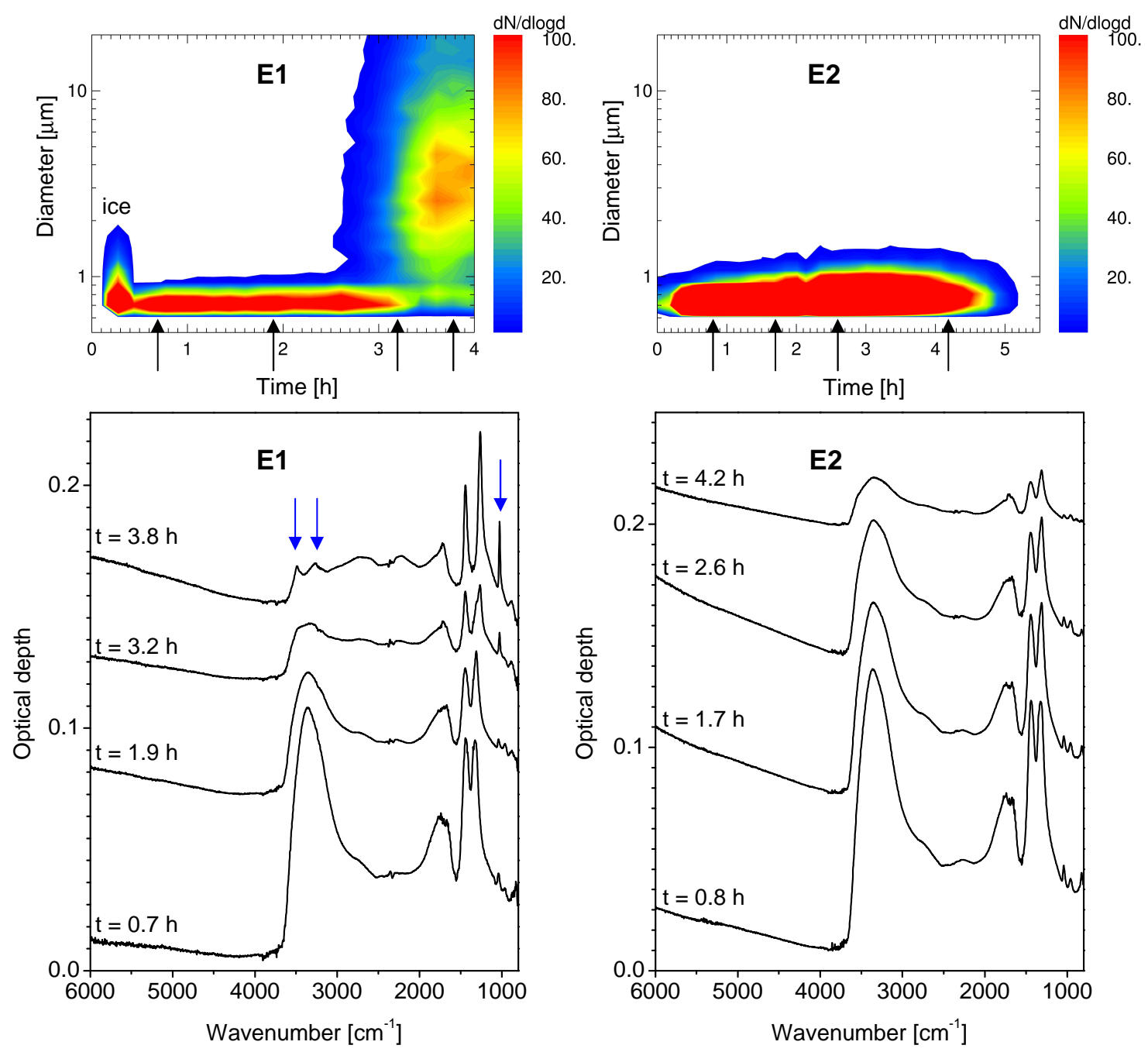

Fig. 2. Time series of size distributions for experiments E1 and E2 measured with the optical particle spectrometer WELAS (upper panels). At several points indicated by arrows the corresponding FTIR spectra are shown in the lower panels. The formation of NAD during experiment E1 can be clearly identified by the change in the optical features marked with blue arrows (for details cf. text). In experiment E2 no change in these features can be observed. Consequently, the WELAS size distributions show no significant change over the course of the experiment. Please note that particle sizes for the NAD crystals are overestimated by the WELAS spectrometer because of their asphericity (see text for details). FTIR-spectra are shifted vertically for clarity.

The composition of the droplets was monitored in 2-3 min intervals by in-situ-FTIR-spectroscopy while the aerosol was generated. Thereby it was possible to adjust the carrier gas flows through the saturators to achieve the desired composition which was typically $45 \mathrm{wt} \%$ (三 molar fraction of 0.2 ) $\mathrm{HNO}_{3}$. The procedure was stopped when a mass concentration of about $1 \mathrm{mg} \mathrm{NO}_{3}^{-} \mathrm{m}^{-3}$ had accumulated, which took about $20-30 \mathrm{~min}$.

This initial mass concentration was chosen to ensure that FTIR-spectroscopy, the filter measurements, and the WELAS size distribution measurements would produce reliable data with good signal-to-noise ratios even at the end of an experiment when the depletion of aerosol mass due to wall losses had led to $\mathrm{NO}_{3}^{-}$concentrations of only $0.2 \mathrm{mg} \mathrm{m}^{-3}$.
During the course of an experiment, the composition and mass concentration of the $\mathrm{HNO}_{3} / \mathrm{H}_{2} \mathrm{O}$-droplets were monitored by recording FTIR extinction spectra in time intervals of about $10 \mathrm{~min}$. The FTIR composition data were also used to calculate saturation ratios with respect to NAD and NAT with the AIM model (Clegg et al., 1998). Only in experiment E3 where FTIR spectra could only be measured for the first hour and were not available for the rest of the experiment due to technical problems, we used water vapor data and compositions of the droplets from model runs to derive the saturation ratios for NAD. The lower panels in Fig. 2 show some sample spectra taken from two experiments. The formation of a new phase could also be detected with this technique as can be seen in the left part of this figure 
Table 1. Summary of data and parameters for the three experiments discussed in this paper. Values are given for two points where nucleation rates were calculated by the formulas described in Sect. 4 . The parameters listed are total pressure $\left(p_{g}\right)$, gas temperature $\left(T_{g}\right)$, experimental time $(t)$, and the time interval $(\Delta t)$ for which data were used to calculate the nucleation rates. FTIR spectra were used to retrieve the weight fraction $\left(f_{\mathrm{W}, \mathrm{NA}}\right)$ and the molar fraction of nitric acid $\left(X_{\mathrm{NA}}\right)$. The AIM model Clegg et al. (1998) was used to determine supersaturations with respect to NAD $\left(S_{\mathrm{NAD}}\right)$ and NAT $\left(S_{\mathrm{NAT}}\right)$ using FTIR composition retrievals. Lognormal size distributions were fitted using WELAS size distributions and provided number concentrations $(N)$, mean particle diameters $\left(d_{p}\right)$, and geometric standard deviations $\left(\sigma_{g}\right)$ for the liquid aerosols.

\begin{tabular}{lcccccc} 
Experiment & \multicolumn{2}{c}{$\mathrm{E} 1$} & \multicolumn{2}{c}{$\mathrm{E} 2$} & & E3 \\
\hline Physical parameters: & & & & & & \\
$T_{g}(\mathrm{~K})$ & 192.2 & 192.1 & 197.1 & 197.0 & 195.8 & 195.8 \\
$p_{g}(\mathrm{hPa})$ & 164.5 & 163.5 & 174.1 & 172.9 & 180.0 & 180.0 \\
$t(\mathrm{~h})$ & 2.4 & 2.8 & 3.0 & 3.5 & 2.3 & 2.5 \\
$\Delta t(\mathrm{~s})$ & 2400 & 2400 & 3600 & 3600 & 1240 & 1240 \\
Aerosol parameters: & & & & & & \\
$f_{\mathrm{W}, \mathrm{NA}}$ & 0.57 & 0.58 & 0.55 & 0.56 & 0.56 & 0.57 \\
$X_{\mathrm{NA}}$ & 0.27 & 0.28 & 0.26 & 0.27 & 0.27 & 0.27 \\
$S_{\mathrm{NAD}}$ & 9.67 & 10.2 & 6.59 & 7.06 & 7.71 & 7.80 \\
$S_{\mathrm{NAT}}$ & 25.5 & 26.0 & 19.4 & 19.2 & 20.4 & 20.3 \\
Lognormal parameters for droplets: & & & & & & \\
$N\left(\mathrm{~cm}^{-3}\right)$ & $4.9 \times 10^{4}$ & $4.4 \times 10^{4}$ & $3.1 \times 10^{4}$ & $2.4 \times 10^{4}$ & $1.4 \times 10^{4}$ & $1.0 \times 10^{4}$ \\
$d_{p}(\mathrm{~nm})$ & 255 & 255 & 290 & 290 & 225 & 225 \\
$\sigma_{g}$ & 1.34 & 1.34 & 1.38 & 1.38 & 1.64 & 1.64 \\
Nucleation rates: & & & & & & \\
$J_{v}\left(\mathrm{~cm}^{-3} \mathrm{~s}^{-1}\right)$ & $4 \times 10^{6}$ & $2 \times 10^{7}$ & $<4 \times 10^{4}$ & $<6 \times 10^{4}$ & $4 \times 10^{5}$ & $6 \times 10^{5}$ \\
$J_{S}\left(\mathrm{~cm}^{-2} \mathrm{~s}^{-1}\right)$ & $2 \times 10^{1}$ & $1 \times 10^{2}$ & $<3 \times 10^{-1}$ & $<4 \times 10^{-1}$ & $2 \times 10^{0}$ & $4 \times 10^{0}$ \\
$J_{s}\left(\mathrm{~cm}^{-2} \mathrm{~s}^{-1}\right.$ ) calc. (Tabazadeh et al., 2002) & $1.3 \times 10^{3}$ & $2.5 \times 10^{3}$ & $4.6 \times 10^{2}$ & $8.2 \times 10^{2}$ & $9.2 \times 10^{2}$ & $9.2 \times 10^{2}$ \\
\hline & & & & & & \\
\hline & & & & & &
\end{tabular}

(experiment E1). Since the newly formed solid phase is generally more stable than the remaining liquid droplets the crystals grow to larger sizes and thus can be differentiated from the droplets by size. This can be seen in the upper left panel of Fig. 2 where the size distributions for experiment E1 are plotted against time. The second mode of large particles at $t=3.2 \mathrm{~h}$ are NAD particles. We used a threshold size to distinguish between these two modes and to integrate the NAD part of the size distribution to obtain total number concentrations for NAD as plotted in panels (f) in Figs. 3-5.

Furthermore, the total nitrate mass was measured by drawing air samples through nylon filters for time intervals of 30$60 \mathrm{~min}$. The collected nitric acid on these filters was then dissolved in $6 \mathrm{ml}$ of distilled water and analyzed by means of ion chromatography. To avoid losses upon sampling, the tubes to the filter were heated to temperatures above $20^{\circ} \mathrm{C}$ and a sandwich of 2 filters was used. Test runs showed that a second backup filter was needed at high $\mathrm{HNO}_{3}$ concentrations to achieve a high enough sampling efficiency. This second filter could contain up to $10 \%$ of the total nitrate mass for an individual measurement.

\section{Results}

\subsection{Experimental observations}

The discussion in this paper emphasizes three experiments carried out at temperatures of $193 \mathrm{~K}$ (denoted E1), $197 \mathrm{~K}$ (denoted E2), and $196 \mathrm{~K}$ (denoted E3). As an overview, time series of temperature, pressure, concentrations (water, nitric acid, aerosol mass, and number concentration), and particle compositions are shown for experiments E1 through E3 in Figs. 3-5. Experimental conditions and results including derived nucleation rates are summarized in Table 1.

The temperatures (panels a in Figs. 3-5) were slightly decreasing from 194 to $192 \mathrm{~K}$ during experiment E1 and from 197.5 to $197 \mathrm{~K}$ during experiment E2. The pressure (cf. panels b) also decreased during these experiments mainly due to sampling losses. Experiment E3 was held at a constant temperature of $195.8 \mathrm{~K}$. The pressure was kept close to $180 \mathrm{hPa}$ by replenishing dry synthetic air if the pressure dropped by more than $0.3 \mathrm{hPa}$ due to sampling.

The relative humidity (panels $\mathrm{c}$ ) as measured by the TDL spectrometer is close to $100 \%$ with respect to ice during aerosol generation and decreases continuously after the aerosol production was stopped. Since the TDL spectrometer 


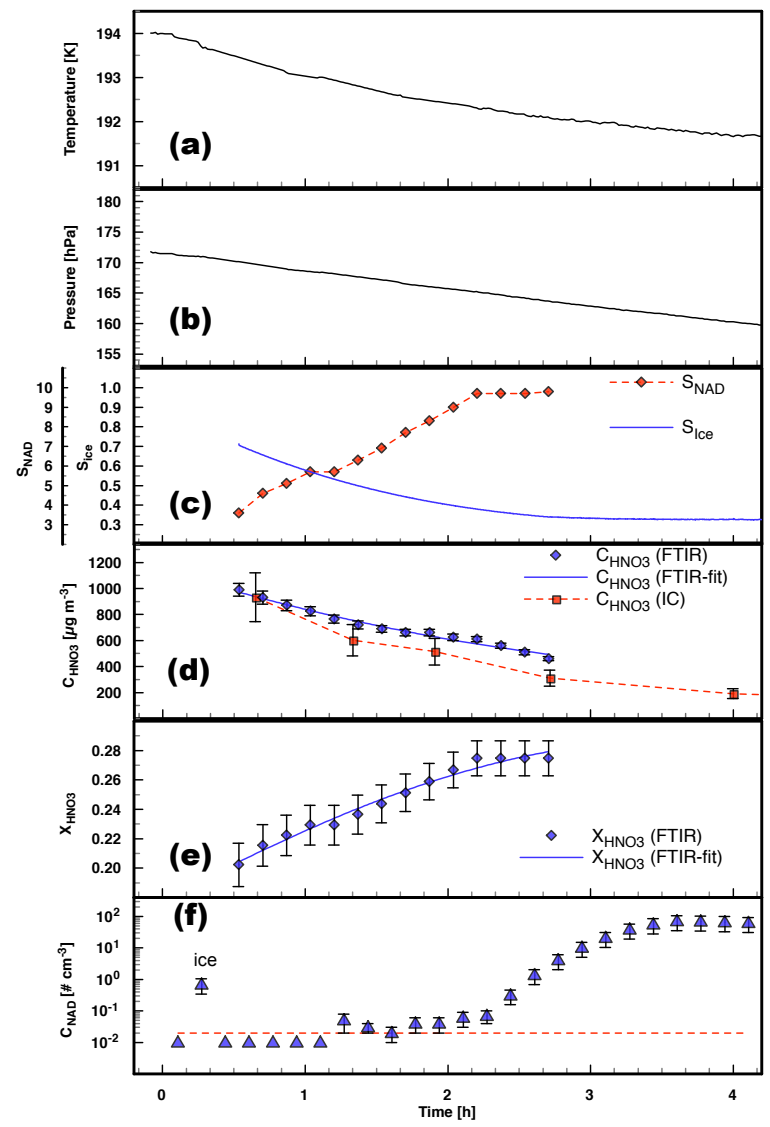

Fig. 3. Time series of temperature (panel a), pressure (panel b), saturation ratios with respect to ice and NAD (panel c), aerosol mass (panel d) derived from FTIR and ion chromatography (IC), aerosol composition (panel e), and NAD crystal number concentrations (panel f) for experiment E1. For details see Sect. 3.1 of the text.

failed to operate in experiment E1, the vapor concentrations from the model simulation are taken instead (cf. companion paper Möhler et al., 2006).

Due to losses of the trace gases to the chamber walls the total aerosol mass decreases with time (panel d) since equilibrium vapor pressures are reestablished continuously by the evaporation from the aerosol particles. Since both gases have different vapor pressures, different diffusivities, and different adsorption constants for the deposition to the chamber walls, the composition of the droplets changes gradually towards higher concentrations of nitric acid (panel e). As a direct result of this change in composition, the saturation ratio with respect to nitric acid dihydrate (NAD) rose (cf. panel c Fig. 3) and induced the formation of solid NAD particles in experiments E1 and E3. Since more highly concentrated solutions of nitric acid have a lower saturation vapor pressure for water, relative humidity decreases as the droplets become higher concentrated (cf. panel c).

Both the changes in composition and the formation of

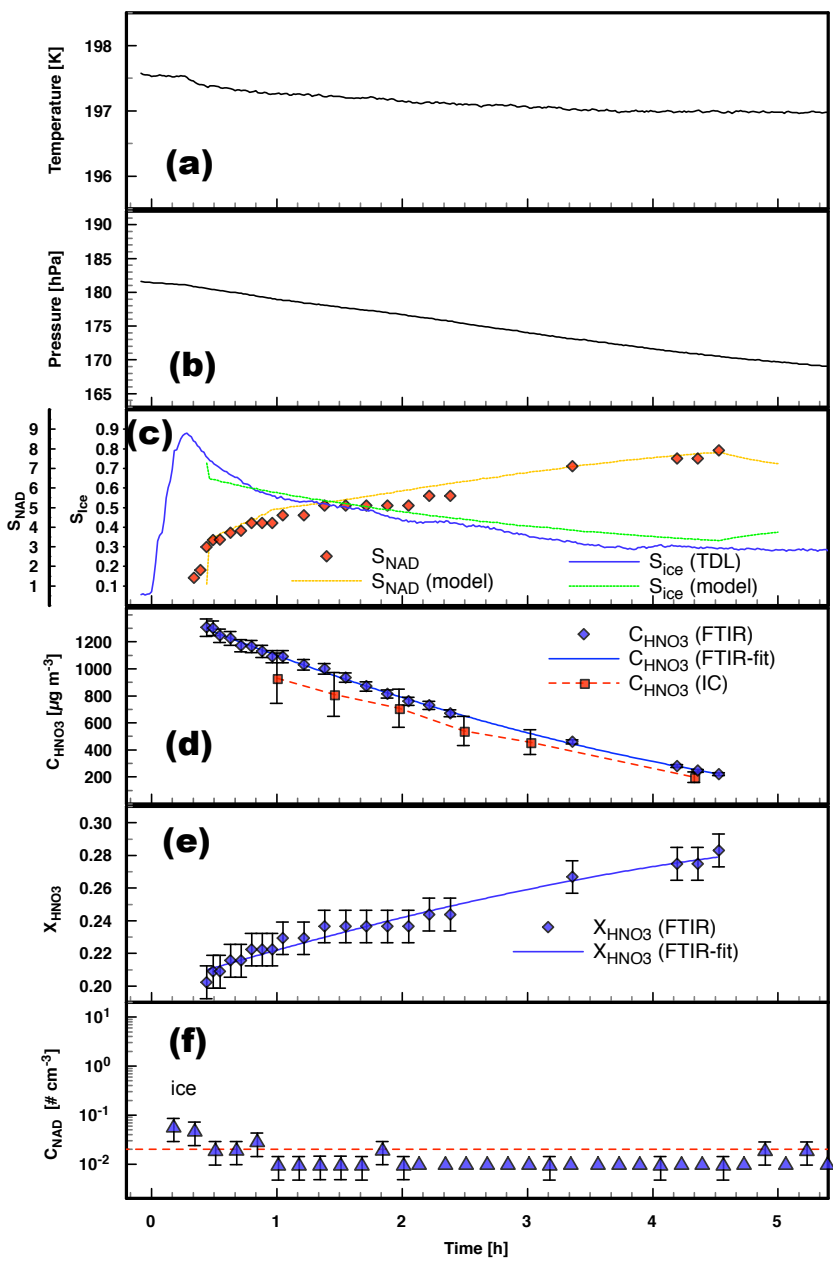

Fig. 4. Time series of temperature (panel a), pressure (panel b), saturation ratios with respect to ice and NAD (panel c), aerosol mass (panel d) derived from FTIR and ion chromatography (IC), aerosol composition (panel e), and NAD crystal number concentrations (panel f) for experiment E2. For details see Sect. 3.1 of the text.

NAD particles were observed by means of FTIR spectroscopy (cf. Fig. 2).

The change in composition of the liquid droplets is represented in the spectra by an increasing intensity of the doublet feature of the nitrate ion between 1300 and $1500 \mathrm{~cm}^{-1}$ relative to the $\mathrm{OH}$ stretching regime at about $3300 \mathrm{~cm}^{-1}$ (cf. Fig. 2). The nucleation of $\alpha-\mathrm{NAD}$ is clearly indicated by the development of a new sharp nitrate vibration feature at $1030 \mathrm{~cm}^{-1}$. This symmetric NO stretching mode $v_{1}\left(\mathrm{NO}_{3}^{-}\right)$ is only active for NAD and not for NAT or the monohydrate NAM (Grothe et al., 2004; Fernandez et al., 2003). Further indicators for the formation of $\alpha$-NAD are the two distinct peaks at 3490 and $3260 \mathrm{~cm}^{-1}$ which replace the broad extinction band of the liquid droplets (blue arrows in Fig. 2 at $t=3.8 \mathrm{~h}$ for experiment E1 indicate the $\alpha$-NAD features discussed in this section). A quantitative analysis of the $\alpha$ - 


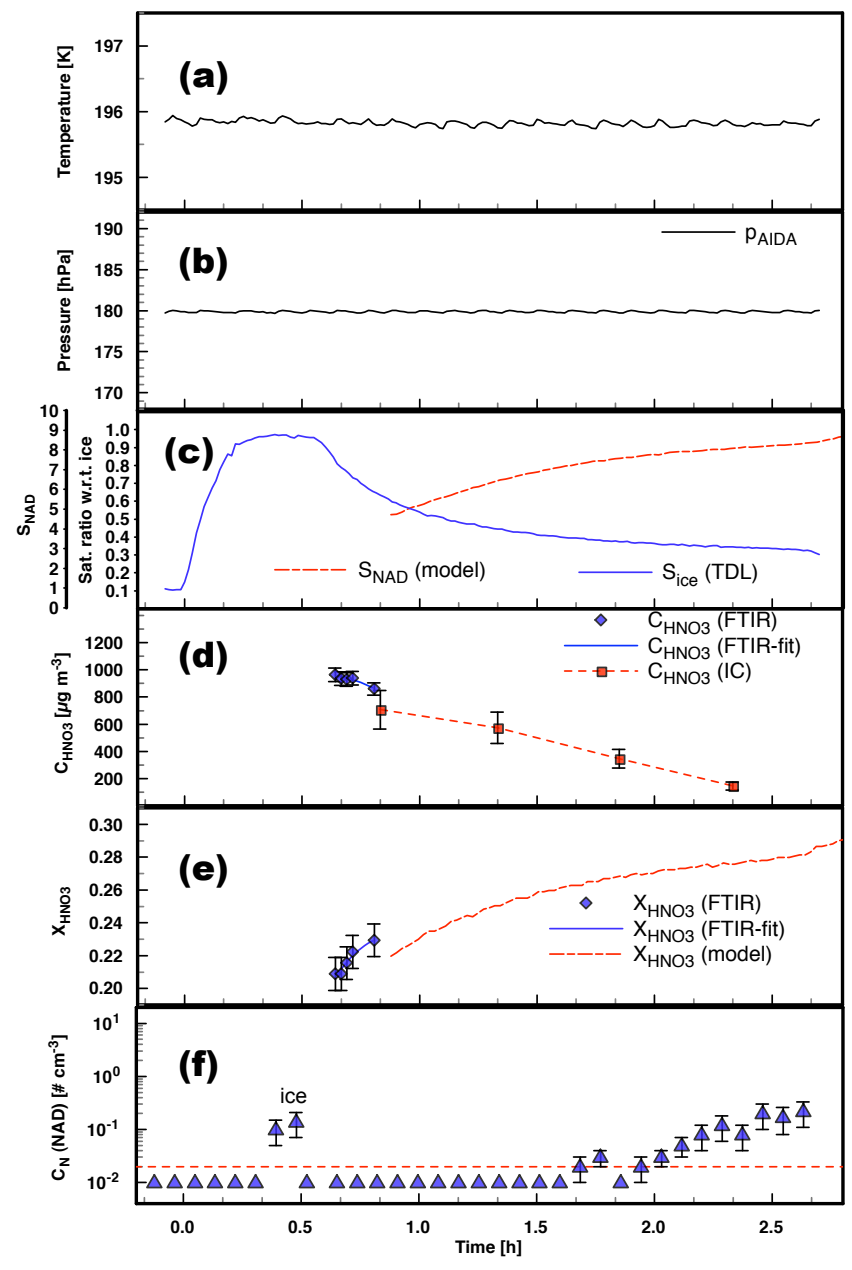

Fig. 5. Time series of temperature (panel a), pressure (panel b), saturation ratios with respect to ice and NAD (panel c), aerosol mass (panel d) derived from FTIR and ion chromatography (IC), aerosol composition (panel e), and NAD crystal number concentrations (panel f) for experiment E3. Due to operational problems, $\mathrm{HNO}_{3}$ concentrations could only be retrieved from the FTIR spectra for the first phase of the experiment. For details see Sect. 3.1 of the text.

NAD spectra using T-matrix calculations indicates that the new phase consists of strongly aspherical $\alpha$-NAD crystals. Best agreement between measured and calculated extinction spectra was obtained by T-matrix fits assuming oblate particle shapes with aspect ratios greater than five. For a thorough discussion of this analysis consult Wagner et al. (2005). (Please note that experiment E1 corresponds to B2 in this reference.) There is no evidence from the FTIR spectra that at any time during our experiments NAT particles were formed.

Since the newly nucleated phase is thermodynamically more stable (lower saturation vapor pressures) than the liquid droplets, the $\alpha$-NAD particles consume water and nitric acid at the expense of the remaining liquid particles. Hence, $\alpha$-NAD particles grow while liquid droplets evaporate until

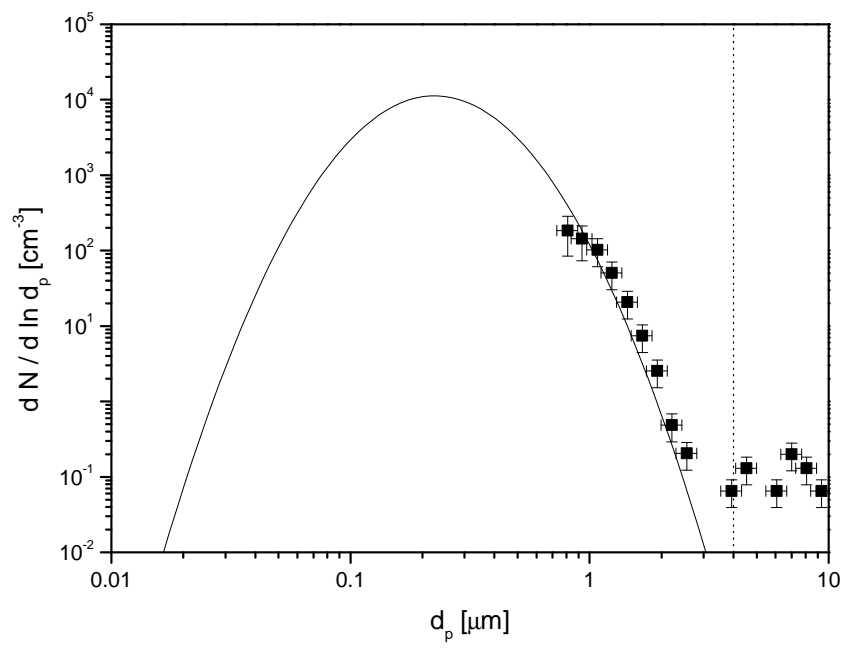

Fig. 6. WELAS size distribution of a mixture of droplets and NAD crystals during the nucleation phase (at $2.3 \mathrm{~h}$ experimental time) of experiment E3 (symbols). The solid line represents the log-normal fir against the data which is further constrained by the total aerosol mass. The dashed line illustrates the threshold beeing used to differentiate between droplets and crystals.

they vanish entirely. This behavior can be clearly seen in the WELAS size distributions in Fig. 2 during the $\alpha$-NAD phase for experiment E1. A second mode of growing particles $(\alpha-$ NAD) evolves after about $2 \mathrm{~h}$ of experiment time with particle sizes of $>1 \mu \mathrm{m}$ in contrast to the liquid droplets which were well below $1 \mu \mathrm{m}$. The difference in size is used to differentiate between both particle classes in order to estimate number concentrations for the $\alpha$-NAD crystals (all particles larger than $1.5 \mu \mathrm{m}$ are counted as NAD, cf. panels f) in experiment E1. These threshold depends on the size distribution of the liquid droplets and is set in such a way that no droplets could be miscounted as NAD crystals (cf. Fig. 6). Hence, different threshold sizes for NAD particles were defined for the other experiments (E2: $4.0 \mu \mathrm{m}$ and E3: $4.0 \mu \mathrm{m}$ ). We estimate the detection limit for these thresholds as 0.02 NAD particles $\mathrm{cm}^{-3}$. This limit is indicated with a dashed line in panels (f) of Figs. 3-5, hence all data points below this limit indicate that NAD particles are absent. In fact, data points which were zero were set to 0.01 in these graphs to become visible (but without error bars for differentiation).

In the beginning of some experiments a few larger particles could be observed and disappeared after some minutes (cf. the first half hour in the upper left panel in Fig. 2, labeled as ice). As evidenced by FTIR-spectroscopy those were ice crystals which formed during the aerosol production phase out of the highly supersaturated vapors at the end of the inlet tube. Since theses particles evaporated after some minutes and conditions remained below ice saturation throughout the experiment we believe that these particles had no influence on the rest of the experiment and especially on the nucleation of NAD. 
When interpreting the size distributions of the WELAS spectrometer one has to be aware of the fact that particle sizes are calculated from the scattering intensity $90^{\circ}$ relative to the incident light source. For non-spherical particles, the scattering intensity in that direction is enhanced (cf. Zakharova and Mishchenko, 2000). Since we know from the analysis of the FTIR spectra (see Wagner et al., 2005, for a detailed discussion) that the NAD particles in experiment E1 are strongly aspherical, the WELAS spectrometer overestimates the size for NAD particles by an unknown factor. Regardless, this effect helps in differentiating NAD particles from liquid droplets by particle size, or, more precisely, scattering intensity in $90^{\circ}$.

\section{Determination of nucleation rates}

As listed in Table 1 we derived nucleation rates for two different time intervals for each experiment. Since the nucleation rate $J_{v}$ for classical volume based nucleation defines the rate of formation of particles of the new phase per unit time and unit volume we used total nitrate mass $m_{\mathrm{NO}_{3}^{-}}$(measured by FTIR), the density for the droplets $\rho$ (estimated to be $1.5 \mathrm{~g} \mathrm{~cm}^{-3}$ ), and the weight fraction of nitric acid $f_{\mathrm{w}, \mathrm{NA}}$ (derived from FTIR) to calculate the total volume of all nitric acid solution droplets:

$V_{\mathrm{NA}}=\frac{m_{\mathrm{NO}_{3}^{-}}}{f_{\mathrm{W}, \mathrm{NA}} \cdot \rho}$.

Using the total droplet volume and the change in NAD particle concentration $\Delta N_{\mathrm{NAD}}$ for a given interval divided by the duration of the interval $\Delta t$ one can calculate $J_{v}$ :

$J_{v}=\frac{\Delta N_{\mathrm{NAD}}}{\Delta t \cdot V_{\mathrm{NA}}}$.

Since no nucleation was detectable in experiment E2 we used the lowest detectable increase in particle concentration $\left(0.1 \mathrm{~cm}^{-3}\right)$ to estimate an upper limit for the nucleation rate in that case.

We also tried to extract surface nucleation rates from our data set in order to test which of the mechanisms discussed in the introduction mirrors our experimental findings best. In contrast to Eq. (1) for the total particle volume we need to estimate a particle size distribution in order to obtain the total surface area of all nitric acid solution droplets. We assume a log-normal type distribution for the liquid droplets out of which NAD may form. The total surface $S_{\mathrm{NA}}$ of all particles is then

$S_{\mathrm{NA}}=N \pi d_{\bar{s}}^{2}$

and can be expressed in terms of the lognormal parameters of a count size distribution using the HATCH-CHOATE (Hinds, 1999) conversion function for the diameter of average surface $d_{\bar{s}}$ multiplied by the total number of particles:

$S_{\mathrm{NA}}=N \pi \exp \left(2 \ln ^{2} \sigma_{g}\right) \mathrm{CMD}^{2}$, where $N$ is the total number concentration of all particles, CMD is the count median diameter, and $\sigma_{g}$ is the geometric standard deviation of the lognormal distribution

$\frac{d N}{d \ln d_{p}}=\frac{N}{\sqrt{2 \pi} \ln \sigma_{g}} \exp \left(-\frac{\left(\ln d_{p}-\ln \mathrm{CMD}\right)^{2}}{2\left(\ln \sigma_{g}\right)^{2}}\right)$.

With the total aerosol volume $V_{\mathrm{NA}}$ as obtained by Eq. (1) one can use the HATCH-CHOATE equation for the mass average diameter $d_{\bar{m}}$ to get the following equation:

$V_{\mathrm{NA}}=N \frac{\pi}{6} \exp \left(4.5 \ln ^{2} \sigma_{g}\right) \mathrm{CMD}^{3}$.

Solving this equation for $N$ and inserting in the lognormal distribution reveals a 2 parameter function for $d_{p}$, where the parameters CMD and $\sigma_{g}$ can be obtained by a fit against the part of the size distribution that is accessible to the WELAS spectrometer (cf. Fig. 6). Unfortunately, the fraction of the droplet size distribution which could be measured by the WELAS spectrometer is rather small. The fits thus allows for some variations in CMD and $\sigma_{g}$ which all agreed quite well with the data. However, these variations resulted in rather small changes in the total surface area. Even for the most extreme choices for values of CMD and $\sigma_{g}$, the differences in the total surface area were less than $10 \%$ for two experiments and $25 \%$ for the third. This is thus negligible if compared to the differences between observed and calculated surface nucleation rates. Due to the small radii of the supercooled nitric acid/water solution droplets of less than $.5 \mu$ m only total volume densities but not individual size distribution parameters can be unambiguously retrieved from the FTIR spectra. Hence we can only specify a range of different combinations for the CMD and $\sigma_{g}$ which all represent equivalent solutions to the retrieval problem (Echle et al., 1998). Assuming that the mode widths $\sigma_{g}$ of the droplet distributions are in the range 1.2-1.8, median droplet diameters between $0.5-0.1$ and $0.6-0.2 \mu \mathrm{m}$ are retrieved for experiments E1 and E2, respectively. As can be seen from Table 1, these fit regimes are consistent with the size distribution parameters retrieved from the WELAS measurements. The larger values for $\sigma_{g}$ and CMD for experiment E2 in comparison with experiment E1 are also in accordance with the FTIR measurements. In the droplet spectra of experiment E2 (cf. lower right graph in Fig. 2), the increased scattering intensities at non-absorbing wavelengths above $4000 \mathrm{~cm}^{-1}$ points to larger droplet diameters compared to experiment E1.

The total surface area $S_{\mathrm{NA}}$ as calculated by Eq. (3) is finally used to obtain the surface nucleation rate:

$J_{s}=\frac{\Delta N_{\mathrm{NAD}}}{\Delta t \cdot S_{\mathrm{NA}}}$.

For each experiment, the surface and volume nucleation rates were calculated for two distinct time intervals $\Delta t$ during the nucleation phase. The resulting values together with the parameters for the lognormal size distributions of the droplets and the physical parameters of the experiment are summarized in Table 1. 


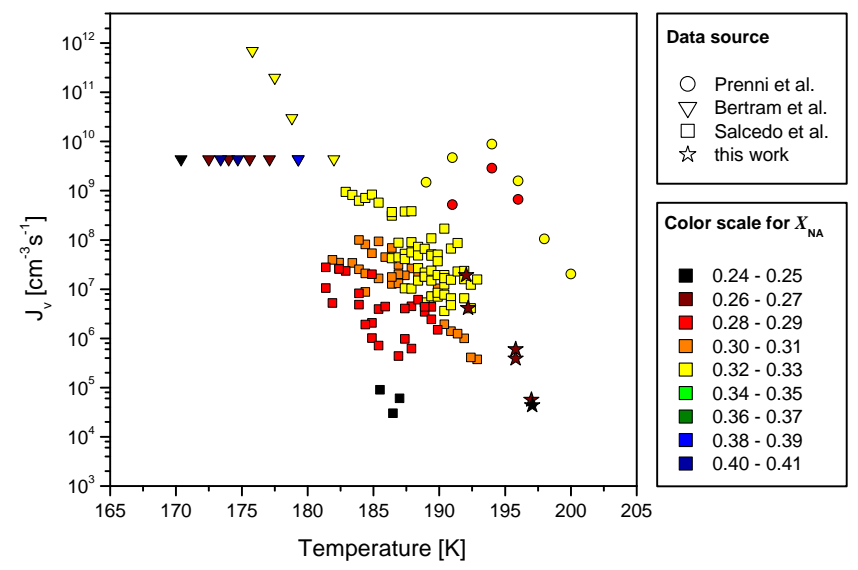

Fig. 7. Volume nucleation rates determined from our experimental data (stars). Also shown are literature data from various sources (cf. text). The individual data points are color coded by the molar fraction for nitric acid $X_{\mathrm{NA}}$.

\section{Discussion}

The volume nucleation rates we obtained from these experiments are plotted against temperature in Fig. 7. Molar fractions of nitric acid are represented by the color coding of the data points. For comparison, we added literature data published by different groups: Prenni et al. (1998); Bertram and Sloan (1998); Bertram et al. (2000); Salcedo et al. (2001). Except for the data by Salcedo et al. we only used experiments with free floating aerosol particles in this comparison to minimize any bias by surface effects that can occur in experiments with particles which are deposited on a substrate. It can be seen that our data fits well to the other data, considering that there is a significant scatter between the individual nucleation rates reported. Classical nucleation theory predicts a strong temperature dependance to lower values of $J$ as temperature rises. These data extend the previously reported nucleation rates to lower values in $J$ in accordance with nucleation theory. Since $J$ is a function of both the temperature and the molar fraction $X_{\mathrm{NA}}$ of a nucleating droplet a direct comparison between different results is only valid for experiments with the similar molar fractions. To overcome this difficulty the discussion of results can be moved from nucleation rates to the Gibbs free energies $\Delta G_{\text {act }}$ of critical cluster formation. This discussion is done thoroughly in the companion paper (Möhler et al., 2006).

The surface nucleation rates which we obtained from our measurements are compared with the theory discussed in Tabazadeh et al. (2002). Figure 8 shows our hypothetical surface nucleation rates together with the calculated values one obtains by using Eqs. (3) and (6) from Tabazadeh et al. (2002). It can be seen that the published parameterization deviates from our data by a factor of 25 in the best case and by more than three orders of magnitude in the worst case. Ad-

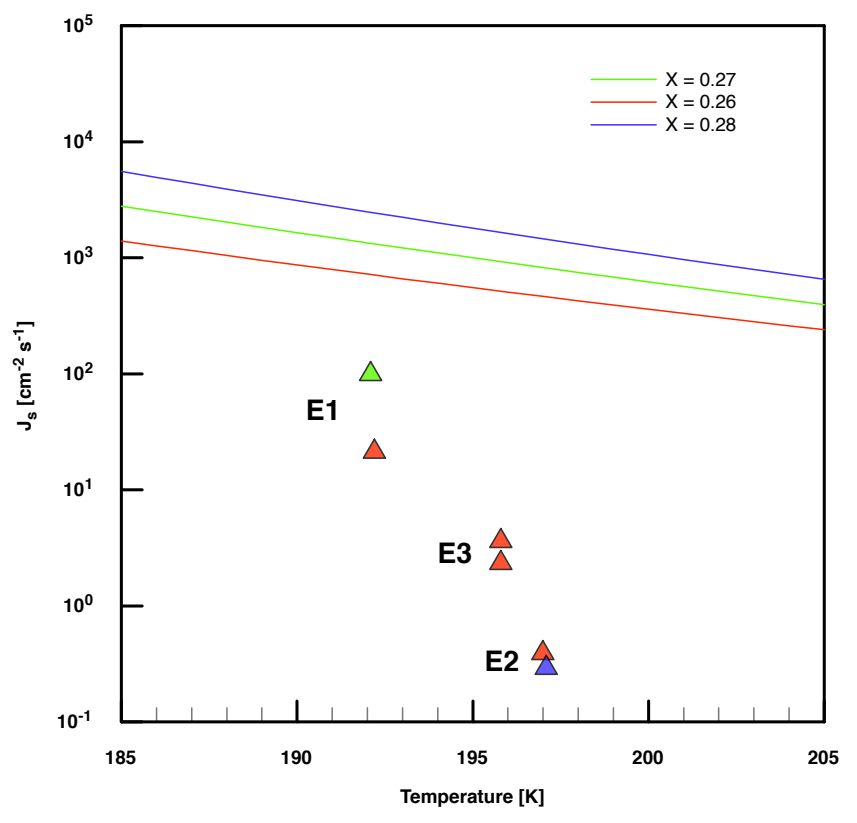

Fig. 8. Hypothetical surface nucleation rates calculated from our experimental data (triangles) versus temperature. The parameterization for $J_{S}$ by Tabazadeh et al. (2002) is depicted as a solid lines. The colors represent different molar fractions for nitric acid.

ditionally, our derived nucleation rates decrease much more strongly with increasing temperature than the parameterizations. Interestingly, the data which were used to derive the parameterization especially in the discussed range for $X_{\mathrm{NA}}$ of about 0.27 (Salcedo et al., 2001) were obtained with much larger nucleating droplets $(\approx 25 \mu \mathrm{m})$ than in this study $(\approx 0.25 \mu \mathrm{m})$. While these two datasets agree with each other within one order of magnitude for $J_{v}$ (cf. Fig. 7), the disagreement between $J_{s}$ values is much larger and agrees with the difference in surface/volume ratios for these two particle sizes. This is a clear indication that surface nucleation can not explain our experimental findings. This finding is also supported by simulations of our experiments using a microphysical process model. The description and the results of these simulations where different parameterizations are compared to experimental data is the subject of the second part of this paper (Möhler et al., 2006). The findings in this study complement the results by Duft and Leisner (2004) where droplets with diameters of $40 \mu \mathrm{m}$ and larger were used to study the homogeneous nucleation of ice. The authors come to the conclusion that, at least for droplet diameters larger than $8 \mu \mathrm{m}$, the nucleation of ice is a volume-dominated process. This study comes to the same conclusion, hence for smaller droplets and for a different freezing substance.

Tabazadeh et al. (2001) and later Larsen et al. (2004) suggested, that NAT may form directly out of freshly nucleated NAD particles. However, in our experiments where NAD formation was observed, the $\alpha$-NAD particles were stable 
for at least an hour. This is a strong evidence against this hypothesis and is in agreement with the results presented by Worsnop et al. (1993) that NAD particles are stable for long time periods. It is still possible though, that a conversion into NAT takes place at much longer time scales.

\section{Conclusions}

The nucleation of nitric acid dihydrate was investigated in the large aerosol chamber AIDA. Liquid droplets of nitric acid solutions were produced in the chamber and observed for several hours under simulated stratospheric conditions. At conditions with high saturation ratios with respect to NAD (greater than 7) the nucleation and growth of solid particles could be detected in two out of three experiments with an optical particle spectrometer. These particles were unambiguously identified as $\alpha$-NAD by in-situ FTIR-spectroscopy. We used our data to deduce nucleation rates for NAD for both volume and surface based nucleation. Our volume based nucleation rates, which cover the range 192-197 K, agree well with the general temperature trend of data published by other authors (cf. Fig. 7). Note that the vast majority of these data were measured below $190 \mathrm{~K}$. Because of the complex and non-linear relation between nucleation rates, temperature and molar composition of the nucleating droplets a better approach to compare our results with literature data is to deploy nucleation theory and use the relation between temperature and the Gibbs free energy of activation $\Delta G_{\text {act }}$. This is done thoroughly in the second part of this publication (Möhler et al., 2006) and is thus not discussed here. However, the hypothetical surface based nucleation rates we derive from our measurements do not agree with parameterizations published by Tabazadeh et al. (2002). In particular, our nucleation rates differ by factors of 25 to $>1000$ from those which were calculated using the parameterization. We therefore conclude that surface based nucleation cannot explain the formation of NAD under the conditions of our experiments.

In some of our experiments we had ice crystals in the chamber directly after particle generation. Since the interior of the AIDA chamber was subsaturated with respect to ice, these solid particles evaporated and vanished finally while the gas phase was constantly supersaturated with respect to NAD and also NAT. Therefore we can exclude an effective direct nucleation of NAD or NAT on the surface of evaporating ice crystals since NAD formation took place at least one hour after the ice crystals disappeared (Luo et al., 2003). Additionally, we did not observe any formation of NAT while NAD particles were stable over a period af one hour. This refutes the hypothesis that NAT may form out of freshly nucleated NAD particles (Tabazadeh et al., 2001). However, a conversion of NAD into NAT cannot be ruled out for periods much longer than one hour.

Acknowledgements. Running the AIDA facility for freezing experiments was only possible with continuous support by all staff members, especially S. Voigt, R. Buschbacher, E. Kranz, and G. Scheurig. We would also like to thank S. L. Clegg et al. for the opportunity to use the AIM model at http://mae.ucdavis.edu/wexler/aim (Clegg et al., 1998). Helpful discussions with D. Knopf, B. P. Luo, T. Koop, P. Spichtinger, U. Schurath, and T. Peter are also acknowledged. This work has been funded by BMBF (AFO2000 project POSTA, 07ATF04) and by the European Commission (FP5 project CIPA, EVK2-CT200000095).

Edited by: B. Kärcher

\section{References}

Benz, S., Megahed, K., Mohler, O., Saathoff, H., Wagner, R., and Schurath, U.: T-dependent rate measurements of homogeneous ice nucleation in cloud droplets using a large atmospheric simulation chamber, J. Photochem. Photobiol. A-Chemistry, 176, 208217, 2005.

Bertram, A. K. and Sloan, J. J.: Temperature-dependant nucleation rate constants and freezing behaviour of submicron nitric acid dihydrate aerosol particles under stratospheric conditions, J. Geophys. Res., 103, 3553-3561, 1998.

Bertram, A. K., Dickens, D., and Sloan, J. J.: Supercooling of type 1 polar stratospheric clouds: The freezing of submicron nitric acid aerosols having HNO3 mol fractions less than 0.5, J. Geophys. Res., 105, 9283-9290, 2000.

Carslaw, K. S., Luo, B., Clegg, S. L., Peter, T., Brimblecombe, P., and Crutzen, P. J.: Stratospheric aerosol growth and HNO3 gas phase depletion from coupled HNO3 and water uptake by liquid particles, Geophys. Res. Lett., 21, 2479-2482, 1994.

Clegg, S. L., Brimblecombe, P., and Wexler, A. S.: Thermodynamic model of the system $\mathrm{H}+-\mathrm{NH} 4+-\mathrm{SO} 4$ 2- -NO3- - H2O at tropospheric temperatures, Journal of Physical Chemistry A, 102, 2137-2154, 1998.

Crutzen, P. and Arnold, F.: Nitric-acid cloud formation in the cold antarctic stratosphere - A major cause for the springtime ozone hole, Nature, 324, 651-655, 1986.

Drdla, K. and Browell, E. V.: Microphysical modeling of the 19992000 Arctic winter: 3. Impact of homogeneous freezing on polar stratospheric clouds, J. Geophys. Res., 109, D10 201, 2004.

Duft, D. and Leisner, T.: Laboratory evidence for volumedominated nucleation of ice in supercooled water microdroplets, Atmos. Chem. Phys., 4, 1997-2000, 2004, http://www.atmos-chem-phys.net/4/1997/2004/.

Ebert, V., Teichert, H., Giesemann, C., Saathoff, H., and Schurath, U.: Fibre-coupled in-situ laser absorption spectrometer for the selective detection of water vapour traces down to the ppb-level, Technisches Messen, 72, 23-30, 2005.

Echle, G., von Clarmann, T., and Oelhaf, H.: Optical and microphysical parameters of the Mt. Pinatubo aerosol as determined from MIPAS-B mid-IR limb emission spectra, J. Geophys. Res.Atmos., 103, 19 193-19211, 1998.

Farman, J., Gardiner, B., and Shanklin, J.: Large losses of total ozone in antarctica reveal seasonal $\mathrm{ClOx} / \mathrm{NOx}$ interaction, $\mathrm{Na}-$ ture, 315, 207-210, 1985.

Fernandez, D., Botella, V., Herrero, V., and Escribano, R.: A theoretical study of the structure and spectra of nitric acid hydrates crystals, J. Phys. Chem. B, 107, 10 608-10 614, 2003. 
Grothe, H., Myhre, C., and Tizek, H.: Vibrational spectra of nitric acid dihydrate (NAD), Vibrational Spectroscopy, 34, 55-62, 2004.

Hinds, W. C.: Aerosol Technology, Wiley, New York, Chichester, Weinheim, Brisbane, Singapore, Toronto, 1999.

Hopfner, M., Luo, B., Massoli, P., Cairo, F., Spang, R., Snels, M., Di Donfrancesco, G., Stiller, G., von Clarmann, T., Fischer, H., and Biermann, U.: Spectroscopic evidence for NAT, STS, and ice in MIPAS infrared limb emission measurements of polar stratospheric clouds, Atmos. Chem. Phys., 6, 1201-1219, 2006, http://www.atmos-chem-phys.net/6/1201/2006/.

Kay, J. E., Tsemekhman, V., Larson, B., Baker, M., and Swanson, B.: Comment on evidence for surface-initiated homogeneous nucleation, Atmos. Chem. Phys., 3, 1439-1443, 2003,

http://www.atmos-chem-phys.net/3/1439/2003/.

Knopf, D. A., Koop, T., Luo, B., Weers, U., and Peter, T.: Homogeneous nucleation of NAD and NAT in liquid stratospheric aerosols: insufficient to explain denitrification, Atmos. Chem. Phys., 2, 207-214, 2002,

http://www.atmos-chem-phys.net/2/207/2002/.

Larsen, N., Knudsen, B., Svendsen, S., Deshler, T., Rosen, J., Kivi, R., Weisser, C., Schreiner, J., Mauerberger, K., Cairo, F., Ovarlez, J., Oelhaf, H., and Spang, R.: Formation of solid particles in synoptic-scale Arctic PSCs in early winter 2002/2003, Atmos. Chem. Phys., 4, 2001-2013, 2004,

http://www.atmos-chem-phys.net/4/2001/2004/.

Luo, B. P., Voigt, C., Fueglistaler, S., and Peter, T.: Extreme NAT supersaturations in mountain wave ice PSCs: A clue to NAT formation, J. Geophys. Res.-Atmos., 108(D15), 4441, doi:10.1029/2002JD003104, 2003.

McElroy, M., Salawitch, R., Wofsy, S., and Logan, J.: Reductions of antarctic ozone due to synergistic interactions of chlorine and bromine, Nature, 321, 759-762, 1986.

Möhler, O., Buttner, S., Linke, C., Schnaiter, M., Saathoff, H., Stetzer, O., Wagner, R., Kramer, M., Mangold, A., Ebert, V., and Schurath, U.: Effect of sulfuric acid coating on heterogeneous ice nucleation by soot aerosol particles, J. Geophys. Res.-Atmos., 110, D11210, doi:10.1029/2004JD005169, 2005.

Möhler, O., Stetzer, O., Schaefers, S., Linke, C., Schnaiter, M., Tiede, R., Saathoff, H., Krämer, M., Mangold, A., Budz, P., Zink, P., Schreiner, J., Mauersberger, K., Haag, W., Kärcher, B., and Schurath, U.: Experimental investigation of homogeneous freezing of sulphuric acid particles in the aerosol chamber AIDA, Atmos. Chem. Phys., 3, 211-223, 2003,

http://www.atmos-chem-phys.net/3/211/2003/.

Möhler, O., Bunz, H., and Stetzer, O.: Homogeneous nucleation rates of nitric acid dihydrate (NAD) at simulated stratospheric conditions - Part II: Modelling, Atmos. Chem. Phys., 6, 30353047, 2006,

http://www.atmos-chem-phys.net/6/3035/2006/.

Molina, L. and Molina, M.: Production of $\mathrm{Cl} 2 \mathrm{O} 2$ from the selfreaction of the ClO Radical, J. Phys. Chem., 91, 433-436, 1987.

Molina, M.: Heterogeneous chemistry on polar stratospheric clouds, Atmos. Environ. Part A-General Topics, 25, 2535-2537, 1991.

Prenni, A., Onasch, T., Tisdale, R., Siefert, R., and Tolbert, M.: Composition-dependent freezing nucleation rates for $\mathrm{HNO} 3 / \mathrm{H} 2 \mathrm{O}$ aerosols resembling gravity-wave-perturbed stratospheric particles, J. Geophys. Res.-Atmos., 103, 28 439-28 450,
1998.

Salcedo, D., Molina, L. T., and Molina, M. J.: Homogeneous freezing of concentrated aqueous nitric acid solutions at polar stratospheric temperatures, J. Phys. Chem. A, 105, 1433-1439, 2001.

Schreiner, J., Voigt, C., Kohlmann, A., Arnold, F., Mauersberger, K., and Larsen, N.: Chemical Analysis of Polar Stratospheric Cloud Particles, Science, 283, 968-970, 1999.

Seifert, M., Tiede, R., Schnaiter, M., Linke, C., Möhler, O., Schurath, U., and Ström, J.: Operation and performance of a differential mobility particle sizer and a TSI 3010 condensation particle counter at stratospheric temperatures and pressures, J. Aerosol Sci., 35, 981-993, 2004.

Solomon, S.: Stratospheric ozone depletion: A review of concepts and history, Rev. Geophys., 37, 275-316, 1999.

Solomon, S., Garcia, R., Rowland, F., and Wuebbles, D.: On the depletion of antarctic ozone, Nature, 321, 755-758, 1986.

Tabazadeh, A.: Commentary on homogeneous nucleation of NAD and NAT in liquid stratospheric aerosols: insufficient to explain denitrification by Knopf et al., Atmos. Chem. Phys., 3, 863-865, 2003 , http://www.atmos-chem-phys.net/3/863/2003/.

Tabazadeh, A., Jensen, E., Toon, O., Drdla, K., and Schoeberl, M.: Role of the stratospheric polar freezing belt in denitrification, Science, 291, 2591-2594, 2001.

Tabazadeh, A., Djikaev, Y. S., Hamill, P., and Reiss, H.: Laboratory evidence for surface nucleation of solid polar stratospheric cloud particles, J. Phys. Chem. A, 106, 10 238-10 246, 2002.

Teichert, H., Fernholz, T., and Ebert, V.: Simultaneous in situ measurement of $\mathrm{CO}, \mathrm{H} 2 \mathrm{O}$, and gas temperatures in a full-sized coalfired power plant by near-infrared diode lasers, Appl. Opt., 42, 2043-2051, 2003.

Tisdale, R. T., Middlebrook, A. M., Prenni, A. J., and Tolbert, M. A.: Crystallization kinetics of $\mathrm{HNO} 3 / \mathrm{H} 2 \mathrm{O}$ films representative of polar stratospheric clouds, J. Phys. Chem. A, 101, 21122119, 1997.

Tizek, H., Knözinger, E., and Grothe, H.: X-ray diffraction studies on nitric acid dihydrate, Phys. Chem. Chem. Phys., 4, 51285134, 2002.

Voigt, C., Schreiner, J., Kohlmann, A., Zink, P., Mauersberger, K., Larsen, N., Deshler, T., Kroger, C., Rosen, J., Adriani, A., Cairo, F., Di Donfrancesco, G., Viterbini, M., Ovarlez, J., Ovarlez, H., David, C., and Dornbrack, A.: Nitric acid trihydrate (NAT) in polar stratospheric clouds, Science, 290, 1756-1758, 2000.

Wagner, R., Mangold, A., Möhler, O., Saathoff, H., Schnaiter, M., and Schurath, U.: A quantitative test of infrared optical constants for supercooled sulphuric and nitric acid droplet aerosols, Atmos. Chem. Phys., 3, 1147-1164, 2003,

http://www.atmos-chem-phys.net/3/1147/2003/.

Wagner, R., Möhler, O., Saathoff, H., Stetzer, O., and Schurath, U.: Infrared spectrum of nitric acid dihydrate - Influence of particle shape, J. Phys. Chem. A, 109, 2572-2581, 2005.

Worsnop, D. R., Fox, L. E., Zahniser, M. S., and Wofsy, S. C.: Vapor Pressures of Solid Hydrates of Nitric Acid: Implications for Polar Stratospheric Clouds, Science, 259, 71-74, 1993.

Zakharova, N. and Mishchenko, M.: Scattering properties of needlelike and platelike ice spheroids with moderate size parameters, Appl. Opt., 39, 5052-5057, 2000. 